\title{
Design and Study of Real-time Online Assessing System for Marine Power Station Reliability
}

\author{
Zhiliang $\mathrm{Wu}^{*}$, Yubin Yao and Dan Wang \\ College of Marine Electrical Engineering, Dalian Maritime University, Dalian 116026, China \\ ${ }^{*}$ Corresponding author
}

\begin{abstract}
Establish reliability model of marine power station under different working conditions. On this basis, the reliability model database of ship power station system is established. Through the real-time online detecting the different working conditions of the marine power station, the corresponding reliability model of the database is called accordingly, and the reliability of the ship power station is evaluated online and in real time. The results of research have important reference value for the research on reliability and maintainability of marine power station.
\end{abstract}

Keywords-Marine power station; reliability; reliability model; assessment system

\section{INTRODUCTION}

The reliability technology of marine power station is a multidisciplinary and highly integrated engineering technology, which is based on the marine electrical engineering technology and automation control technology. The reliability technology of marine power station has become an important research field in the future development direction of the ship, and it is also the focus of research in the shipbuilding industry and scientific research institutes both at home and abroad. It has great practical value to study the reliability of marine power station as a relatively independent system[1].

\section{Reliability Modeling FOR Marine Power Station}

The marine power station is usually made up of three generator sets. The normal working conditions of the marine power station can be divided into inward and outward port, navigation and berthing conditions. Because the electric load of the marine power station varies under the different operating condition, the number of the generator sets put into operation is also changing. So the marine power station will appear the different operation mode, such as single operation, the parallel operation of the two generator sets and the parallel operation of the three generator sets[2].

The traditional reliability analysis of marine power station usually takes the marine power station as a whole system, which only analyses one operation mode, the parallel operation of the three generator sets. So the reliability model of marine power station is far from the actual marine power station. It only can be draw the general, myopia conclusion, when the reliability of large electrical control system is evaluated according to the conventional series and parallel mathematical model[3].
In order to accurately evaluate the reliability of marine power station, it has great practical significance to get the actual, accurate mathematical model of marine power station reliability, through modeling for reliability of marine power station under different working conditions.

Marine power station is usually composed of three generator sets. In this paper, the reliability of a single generator set denotes by $R_{\mathrm{S}}$, the failure rate of a single generator set denotes by $\lambda_{\mathrm{S}}$.

(1) The condition of inward and outward port is that a ship is in the state of maneuver, or sails at low speed in the harbor. To ensure the reliability, the marine power station is required the parallel operation of the three generator sets under the condition. There are usually two design options[4].

(1) It can meet the requirements of the actual load of the whole ship only when the three generator sets are working properly. At this time, the reliability model of marine power station is the reliability series model which is composed of three identical generator sets. The reliability of diagram is shown in Figure 1.

Under the working condition, failure rate of marine power station: $\lambda_{\mathrm{P}}=3 \lambda_{\mathrm{S}}$, reliability of marine power station: $R_{\mathrm{P}}=\exp \left(-\lambda_{\mathrm{P}} t\right)$, the mean time to failure of marine power station: $\mathrm{MTBF}_{\mathrm{P}}=\int_{0}^{+\infty} R_{\mathrm{P}} \mathrm{d}(t)=\frac{1}{3 \lambda_{\mathrm{S}}}$.

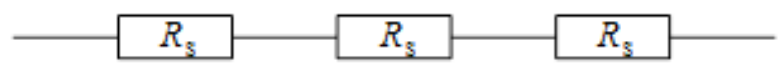

\section{FIGURE I. RELIABILITY DIAGRAM OF MARINE POWER STATION SERIES MODEL}

(2) The marine power station requires that it will meet the requirements of the whole ship's power supply when at least two generator sets of the three are available. Apparently, this system is a typical voting system of $2 / 3(\mathrm{G})$, that two out of three. In other words, the system will break down if only two or more units have a fault. The block diagram of reliability on ship inward and outward port condition is shown in Figure 2.

Under the working condition, the reliability of marine power station: 
$R_{\mathrm{P}}=3 R_{\mathrm{S}}{ }^{2}-2 R_{\mathrm{S}}^{3}=3 \exp \left(-2 \lambda_{\mathrm{S}} t\right)-2 \exp \left(-3 \lambda_{\mathrm{S}} t\right)$, the mean time to failure of marine power station:

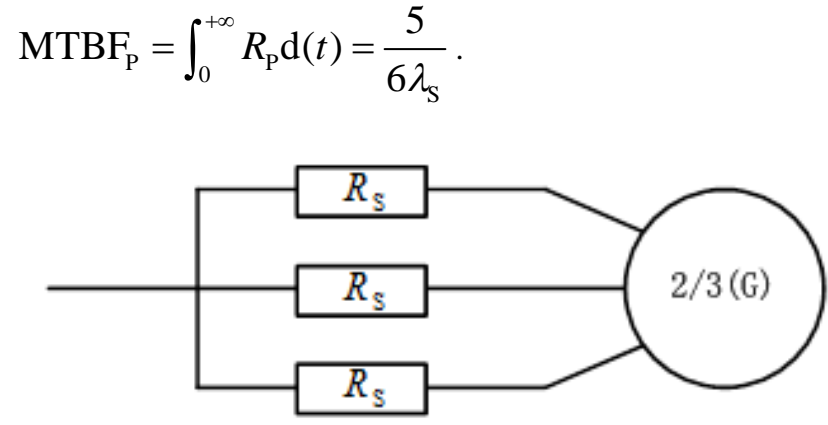

FIGURE II. RELIABILITY DIAGRAM OF MARINE POWER STATION VOTING SYSTEM OF 2/3(G) MODEL

(2) The condition of navigation is that a ship sails at sea at full speed and full load. Under the condition, only one generator set is enough to satisfy the basic need of ship. The block diagram of reliability is a shunt-wound model of three same reliability $R_{\mathrm{S}}$, as the Figure 3 shown.

Under the working condition, the reliability of marine power station: $R_{\mathrm{N}}=R_{\mathrm{S}}{ }^{3}-3 R_{\mathrm{S}}{ }^{2}+3 R_{\mathrm{S}}$, the mean time to failure of marine power station: $\mathrm{MTBF}_{\mathrm{N}}=\int_{0}^{+\infty} R_{\mathrm{N}} \mathrm{d}(t)=\frac{11}{6 \lambda_{\mathrm{S}}}$

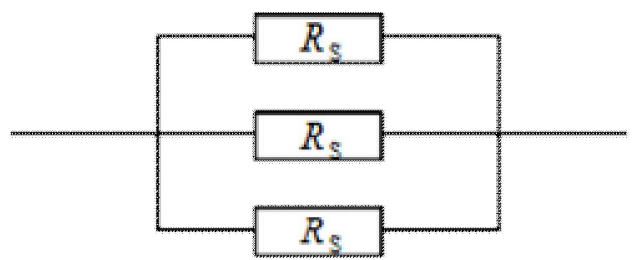

FIGURE III. RELIABILITY DIAGRAM OF MARINE POWER STATION PARALLEL MODEL

(3) The condition of berthing is that a ship docks on the wharf or anchorage without loading operation. Under the condition, only one generator set is needed in the power network. Besides, other two should be shutdown in standby state. Apparently, on the berthing conditions, the station is a cold standby system with three same units, as the Figure 4 shows. If the effect of the conversion device is considered, the reliability model is a model of cold standby system which considers the failure effect of the conversion device. And the conversion device is an automatic switching circuit, when gets the order it can send signals to start a backup. The reliability of the conversion device is $R_{1}$, the Failure rate is $\lambda_{1}$.
Under the working condition, the reliability of marine power station:

$$
\begin{aligned}
R_{\mathrm{B}} & =\exp \left(-\lambda_{\mathrm{S}} t\right)+\frac{\lambda_{\mathrm{S}}}{\lambda_{1}}\left\{\exp \left(-\lambda_{\mathrm{S}} t\right)-\exp \left[-\left(\lambda_{\mathrm{S}}+\lambda_{\mathrm{l}}\right) t\right]\right\} \\
& +\frac{\lambda_{\mathrm{S}}\left(\lambda_{\mathrm{S}}+\lambda_{\mathrm{l}}\right)}{2 \lambda_{\mathrm{l}}^{2}} \bullet \exp \left[-\left(\lambda_{\mathrm{S}}+2 \lambda_{1}\right) t\right]
\end{aligned}
$$

The mean time to failure of marine power station: $\mathrm{MTBF}_{\mathrm{B}}=\frac{1}{\lambda_{\mathrm{S}}}+\frac{1}{\lambda_{\mathrm{S}}+\lambda_{\mathrm{l}}}+\frac{1}{\lambda_{\mathrm{S}}+2 \lambda_{\mathrm{l}}}$. Usually, the failure rate of the conversion device $\lambda_{1}$ is very small, which can be ignored. So, $\mathrm{MTBF}_{\mathrm{B}}=\frac{3}{\lambda_{\mathrm{S}}}$.

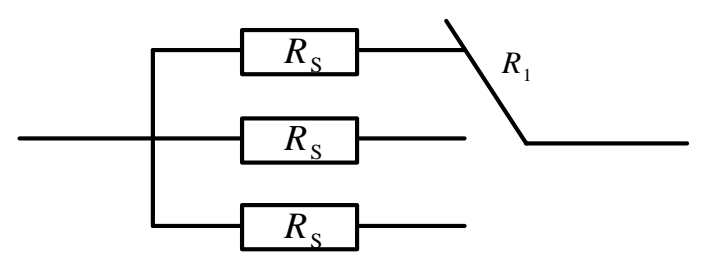
FIGURE IV. THE BLOCK DIAGRAM OF RELIABILITY ON THE
BERTHING CONDITION

\section{DATABASE EstaBlishmENT}

The database is used to store the basic reliability model of marine power station system and the reliability mathematical model of marine power station under different working conditions.

(1) The basic reliability model of marine power station system includes reliability block diagram and mathematical model of series system, reliability block diagram and mathematical model of parallel system, reliability block diagram and mathematical model of $\mathrm{k} / \mathrm{n}(\mathrm{G})$ voting system, reliability block diagram and mathematical model of reserve system, which is composed of cold standby system and warm standby system.

(2) Establish a mathematical model for reliability of marine power station under different working conditions.

\section{Design of Real-time OnLine Assessment System}

Real-time online assessing system of marine power station reliability is composed of reliability model database of marine power station system, reliability mathematical model of marine power station under different working conditions and real-time online assessment system. The reliability model database of marine power station system is used to store the reliability model of marine power station. Real-time online evaluation system calls the corresponding reliability model of system reliability model database, according to the real-time monitoring of marine power station to the current operating conditions, to evaluate the reliability of marine power station. 
The real-time online assessment system of marine power station is composed of the lower computer controller and the upper computer. The lower computer controller is mainly composed of S7-1200 series programmable logic controller (PLC) produced by SIEMENS. The upper computer is used MT8000i which is a kind of HMI conducted by WEINVIEW. The communication method between the PLC and HMI is PROFINET industrial Ethernet.

The process of communication between the lower computer controller and the upper computer, firstly, write the PLC program and establish a physical connection by the RJ45 port. In configuration software of the HMI, click on the "acquire label Information" button, then touch screen will obtain the data block of PLC to complete the connection between the PLC and the touch screen.

The working process of the real-time online assessment system is as follow: an output corresponding to the working condition is generated, which is judged by the lower computer controller PLC. And the real-time working condition will be displayed in the touch screen. There are five display situations, listed as follow:

0-Real-time online assessment system doesn't work

1-The condition of inward and outward port (1)

2-The condition of inward and outward port (2)

3-The condition of navigation

4-The condition of berthing
Touch screen real-time accesses the detection data from the PLC through the network communication. Under the condition of automatic identification, PLC will real-time automatically call the reliability evaluation interface of corresponding working condition and the data in the related database to calculate the reliability index of the condition.

The information acquisition subsystem is used to monitor all kinds of working conditions of the marine power station in real time. And it divides the working condition into the condition of inward and outward port, the condition of navigation and the condition of berthing, according to the working condition of the ship running state[5]. PLC will call the reliability of the corresponding mathematical model according to the working conditions of ship power station, the specific conditions as follow: Under the condition of inward and outward port, the marine power station requires all generator sets or a certain number of them to be put into operation, so the type of the reliability model is the reliability model of the series system or $\mathrm{k} / \mathrm{n}(\mathrm{G})$ voting system. Under the condition of navigation, the marine power station requires a generator set to be put into operation, so the corresponding reliability model is the reliability model of the parallel system. Under the condition of berthing, the marine power station requires a generator set to be put into operation, the others are shutdown in standby state, so the type of the reliability model is the reliability model of the cold standby system. The structure of reliability assessment system for marine power station is shown in Figure 5.

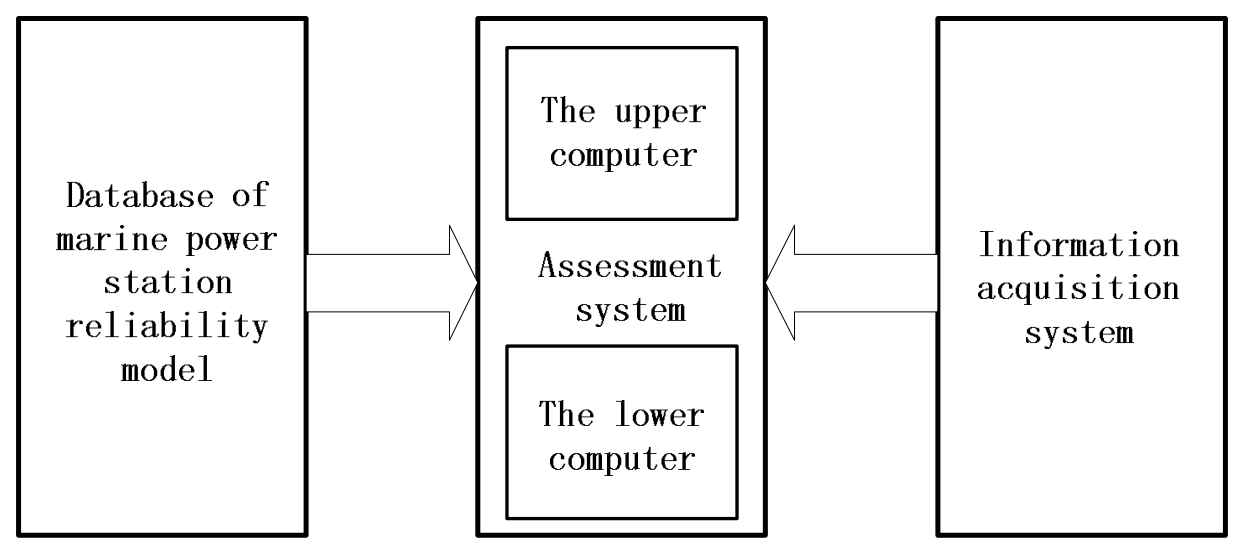

FIGURE V. THE STRUCTURE OF RELIABILITY ASSESSMENT SYSTEM FOR MARINE POWER STATION

\section{CONCLUSION}

The basic reliability model of marine power station system has been established. On this basis, it is an accurate and reliable mathematical model of the marine power station in different conditions to be completed. Through real-time online detection different operation condition, the reliability model of marine power station is called to complete the real-time online reliability assessment of the marine power station under the current working condition.

\section{REFERENCES}

[1] Zhiliang Wu. Reliability engineering and application of ship and port electrical system. Dalian: Dalian Maritime University Press, 2006.

[2] China Classification Society. Classification Rules of Steel Sea-going Vessel(2009). Beijing: China Communications Press, 2009.

[3] Wang Chao, Wang Huifang, Zhang Chi. Study of reliability modeling for relay protection system in digital substations. Power System Protection and Control, 2013,41(3):8-13.

[4] Zhiliang Wu, Yubin Yao and Dan Wang. The Reliability Modeling of Marine Power Station, Mechanical engineering industrial electronics and information (MEIEI2013), 2013, (Part B): 404-407.

[5] Zhiliang Wu. Marine power station. Dalian: Dalian Maritime University Press, 2012. 